\title{
(2) OPEN ACCESS \\ Clinical relevance of the in situ assay for HBV DNA: a cross-sectional study in patients with chronic hepatitis $B$
}

\author{
Danping Liu, ${ }^{1}$ Tong Xu, ${ }^{1}$ Bisheng Shi, ${ }^{1}$ Wei Lu, ${ }^{1}$ Ye Zheng, ${ }^{1}$ Yanling Feng, ${ }^{1}$ \\ Zhenghong Yuan, ${ }^{2}$ Xiaonan Zhang $\odot{ }^{1},{ }^{\prime}$ Zhanqing Zhang'
}

\begin{abstract}
- Additional material is published online only. To view please visit the journal online (http://dx.doi.org/10.1136/ jclinpath-2020-206440)

${ }^{1}$ Shanghai Public Health Clinical Center, Fudan University, Shanghai, China ${ }^{2}$ Key Laboratory of Medical Molecular Virology, Shanghai Medical College of Fudan University, Shanghai, China
\end{abstract}

\section{Correspondence to} Dr Xiaonan Zhang, Shanghai Public Health Clinical Center Fudan University, Shanghai, China; zhangxiaonan@shphc. org.cn

Professor Zhenghong Yuan; zhyuan@shmu.edu.cn Professor Zhanqing Zhang; doctorzzqsphc@163.com

DL, TX and BS contributed equally.

Received 15 January 2020 Revised 10 March 2020 Accepted 13 April 2020 Published Online First 13 May 2020

\section{ABSTRACT}

Aims The visualisation of HBV DNA in liver sections of patients with chronic hepatitis $B(C H B)$ in our previous report uncovered a mosaic distribution of viral antigens and nucleic acids. Here we aim to further explore the clinical utility of the in situ hybridisation (ISH) assay for HBV DNA.

Method ISH of HBV DNA along with immunohistochemistry (IHC) of $\mathrm{HBsAg}, \mathrm{HBCAg}$ and routine histopathology analysis was performed in 313 treatment-naive patients with $\mathrm{CHB}$. Serum HBcrAg and $\mathrm{HBCAb}$ titre were also measured in addition to basic biochemical and virological parameters.

Results The ISH of HBV DNA, HBsAg and $\mathrm{HBCAg}$ showed $95.2 \%, 97.1 \%$ and $42.8 \%$ positive rate, respectively. The staining pattern of HBV DNA differs significantly with that of HBsAg. Intrahepatic HBV DNA exhibited high-level of correlations with viral load, $\mathrm{HBcrAg}$ and $\mathrm{HBsAg}$ titre. In HBeAg-negative patients, higher intrahepatic HBV DNA is associated with histological evidence of liver inflammation and fibrosis, whereas no such trend was observed in HBeAg-positive patients. Finally, a triple staining protocol that combined the detection of HBV DNA, HBsAg and collagen fibre was developed to enable better evaluation of viral replication and antigen expression in the context of disease progression.

Conclusions The ISH assay for HBV DNA reflects the vigour of intrahepatic viral replication. It is complementary to the routine IHC assay for viral antigens and also related to the histopathological progression of liver diseases. The application of the HBV DNA ISH assay may help a better evaluation of virological and pathological condition of patients with $\mathrm{CHB}$.

\section{INTRODUCTION}

The hepatitis $\mathrm{B}$ virus (HBV) infection remains a global public health issue, affecting more than 240 million chronic hepatitis B (CHB) individuals worldwide. ${ }^{1}$ The chronic liver disease caused by the virus leads to liver fibrosis and ultimately hepatocellular carcinoma. ${ }^{2}$ A thorough understanding of the natural history of $\mathrm{CHB}$ has been facilitated by continuous development of assays for major serum virological (HBV DNA and HBV RNA) and immunological (HBV antigens and antibodies) parameters. ${ }^{3}$ Among them, the recently developed HBV core related antigen $(\mathrm{HBcrAg})^{4-6}$ and quantitative $\mathrm{HBcAb}$ titre have shown considerable predictive values. $^{7}$
Although serum biomarkers have been widely used to assess the chronic liver disease, the histopathological examination of liver biopsy remains the gold standard for evaluation of liver pathologies of $\mathrm{CHB} .{ }^{8}$ In addition, immunohistochemistry (IHC) of HBsAg and HBcAg helps clinicians evaluate the virological activities of HBV. ${ }^{9}$ However, the IHC of HBsAg showed limited relationship with the vigour of viral replication, whereas the positive rate of $\mathrm{HBcAg}$ is lower.

We recently established a sensitive in situ hybridisation (ISH) assay for HBV DNA and found its distribution to be distinct from that of HBsAg. ${ }^{10}$ These findings suggested that intrahepatic HBV DNA might represent a novel histological marker complementary to the current IHC examinations. In this study, we sought to further evaluate its sensitivity and specificity in a large group of patients with $\mathrm{CHB}$ and non-HBV hepatitis patients. In addition, the relationship between HBV DNA ISH assay and existing virological/pathological markers was also investigated

\section{MATERIALS AND METHODS \\ Patients and samples}

This study enrolled 313 CHB treatment-naive patients who were admitted into the Department of Hepatobiliary Medicine, Shanghai Public Health Clinical Center and underwent liver biopsy from March 2015 to December 2018. Among them, 163 patients were $\mathrm{HBeAg}$ positive, and 150 patients were $\mathrm{HBeAg}$ negative. The diagnosis for the patients was in accordance with the standard elaborated in the EASL (European Association for the Study of the Liver) 2017 Clinical Practice Guidelines on the management of HBV infection. ${ }^{2}$ The exclusion criteria were as follows: coinfected with other viral hepatitis, HIV, significant alcohol consumption (>20 g per day for men, $>10 \mathrm{~g}$ per day for women), liver pathology indicated drug-induced liver injuries or fatty liver disease and received antiviral therapy in preceding 6 months.

\section{Pathological assessment}

Ultrasound-assisted liver biopsies were performed using a one-second liver biopsy needle (16G). The liver specimens obtained were routinely formalin fixed and paraffin embedded. The tissue paraffin sections were stained with $\mathrm{H} \& \mathrm{E}$, Masson's trichrome and reticulin. Liver pathological assessment was independently evaluated by two 
experienced pathologists who were blinded to the clinical information and employed the Scheuer standard.

IHC of HBsAg and HBcAg were performed using Leical BOND automatic stainer and inspected by pathologists and scored as 0 , 1,2 and 3 corresponding to proportion of the immunolabelled cells of $0 \%,<5 \%, 5 \%-20 \%$ and $>20 \%$, respectively.

\section{Clinical and serological parameters}

Serum samples were obtained within 1 day before or after liver biopsy. Serum HBsAg, HBeAg and anti-HBe were measured by chemiluminescence microparticle immunoassay (CMIA) (Abbott, USA). The detection range of serum HBsAg is 0.05$250 \mathrm{IU} / \mathrm{mL}$, and it was retested with a dilution of 1:500 if the initial test value exceeding the upper detection limit. Serum $\mathrm{HBcAb}$ was measured using CMIA (Chemiluminesence microparticle microparticle immunoassay, Wantai, China), and the detection range was $10^{2} \mathrm{IU} / \mathrm{mL}$ to $10^{5} \mathrm{IU} / \mathrm{mL}$. Serum $\mathrm{HBcrAg}$ was measured by chemiluminescent enzyme immunoassay (Fujirebio, Japan) with the detection range of $10^{3} \mathrm{IU} / \mathrm{mL}$ to $10^{7} \mathrm{IU} /$ $\mathrm{mL}$, and it was retested with a dilution of 1:1000 if the initial test value exceeded the upper detection limit. Serum HBV DNA was quantified using PCR-fluorescence probing assay (Sansure, China) with a detection range of $5 \times 10^{2}$ to $2 \times 10^{9} \mathrm{IU} / \mathrm{mL}$. Serum alanine transferase (ALT) was measured by Abbott Accelerator a3600 full-automatic biochemical analyser (Abbott, USA).

\section{ISH of HBV DNA}

The procedures of hybridisation and amplification were based on our previous study ${ }^{10}$ and performed using the ViewRNA ISH Tissue Assay (Thermo Fisher, Fremont, California, USA). The tissue sections were routinely dewaxed and rehydrated, followed with antigen retrieval, protease digestion and refixation with 4\% formaldehyde for $5 \mathrm{~min}$. The HBV DNA probe (VF6-20095) was designed to target the minus strand sequence (nt2959-837) conserved from genotype A to genotype D. After probe hybridisation and signal amplification, sections were stained with NBT/BCIP (Roche) in developing solution at $37{ }^{\circ} \mathrm{C}$ for 2 hours. Sections were then incubated with antibody to Histone H3 (Cell Signaling Cat No. 14269) followed by HRP-conjugated antibody, and the signal was developed by AEC. The ISH results were examined by pathologists and a score of $0-4$ was given
(0-4, corresponding to approximately $0 \%,<5 \%, 5 \%-10 \%$, $10 \%-20 \%$ and $>20 \%$ ). For HBV DNA-HBsAg-Sirius Red triple staining, after development of DNA signal, anti-HBs antibody (clone: OTI1D3, ZM-0122, ZSBio, Beijing China) was applied to the section followed by anti-mouse/rabbit IgG-HRP (Leica) incubation and development by DAB. Slides were finally stained with Sirius red for $30 \mathrm{~min}$ and washed with distilled water before air-dry and mounting. The slides were scanned by Panoramic Digital Slide Scanner (3DHISTECH). The whole section images were exported and processed with Image to calculate the surface area of the ISH positive cells relative to total tissue area. Fully digitalised whole-section images accompanied by basic clinical parameters were compiled and uploaded onto http://www.hepbatlas.com.

\section{Ethics statement}

All patients provided written consent prior to their inclusion in the study and the collection of clinical samples.

\section{Statistical analysis}

Statistical analyses were performed using Medcalc version 15.8 (Broekstraat, Mariakerke, Belgium) and the R package (corrplot). For continuous variables, median and IQR was used. For categorical variables, frequencies and proportions were used. Comparisons between $\mathrm{HBeAg}$-positive and HBeAg-negative patients were done via Mann-Whitney U test for continuous data and Pearson $\chi^{2}$ test for categorical data. The correlation coefficient was calculated using the Spearman method. Significance was assumed at $\mathrm{p}<0.05$ for all tests.

\section{RESULTS \\ Demographic, clinical and pathological characteristics of study population}

A total of 313 patients with CHB were enrolled in this study. They were categorised into HBeAg-positive $(n=163)$ and HBeAg-negative $(n=150)$ patients. Demographic, clinical and pathological characteristics of study population are shown in table 1 . The male-to-female ratios in these two groups were comparable $(p>0.05)$. The medium age of HBeAg-negative patients was higher than that of HBeAg-positive patients

\begin{tabular}{|c|c|c|c|c|}
\hline & $\begin{array}{l}\text { HBeAg positive } \\
(n=163)\end{array}$ & $\begin{array}{l}\text { HBeAg negative } \\
(n=150)\end{array}$ & $Z^{*} / \chi^{2+}$ & $P$ value \\
\hline Gender (male:female) & $99: 64$ & $91: 59$ & $0.011 t$ & 0.9178 \\
\hline Age (years; M, IQR) & $31(28-37)$ & $42(35-50)$ & 8.600 & $<0.0001$ \\
\hline ALT (U/L; M, IQR) & $69(42-156.75)$ & $35.5(18-107)$ & 4.115 & $<0.0001$ \\
\hline Serum HBsAg (log10 IU/mL; M, IQR) & $4.117(3.691-4.635)$ & $3.296(2.745-3.702)$ & 10.417 & $<0.0001$ \\
\hline Serum anti-HBc (log10 IU/mL; M, IQR) & $3.526(3.211-3.819)$ & $4.225(3.680-4.642)$ & 8.520 & $<0.0001$ \\
\hline Serum HBcrAg (log10 IU/mL; M, IQR) & $8.200(7.700-8.500)$ & $4.1500(3.000-5.800)$ & 13.779 & $<0.0001$ \\
\hline Serum HBV DNA (log10 IU/mL; M, IQR) & $7.314(6.469-7.903)$ & 3.588 (2.699-5.681) & 12.668 & $<0.0001$ \\
\hline HBsAg IHC (0:1:2:3) & $3: 36: 59: 65$ & $10: 65: 52: 23$ & $32.098 t$ & $<0.0001$ \\
\hline HBCAg IHC (0:1:2:3) & $58: 47: 48: 10$ & $121: 26: 3: 0$ & $77.514 \dagger$ & $<0.0001$ \\
\hline HBV DNA-ISH positive area (\%; M, IQR) & $7.949(4.365-15.733)$ & $1.556(0.687-3.685)$ & 10.030 & $<0.0001$ \\
\hline HBV DNA-ISH score (0:1:2:3:4) & 2:14:33:52:61 & $13: 50: 57: 24: 6$ & $89.853 \dagger$ & $<0.0001$ \\
\hline Grade (1:2:3:4) & $95: 57: 11: 0$ & $115: 21: 14: 0$ & $18.372 \dagger$ & 0.0001 \\
\hline Stage (1:2:3:4) & $71: 60: 11: 21$ & $90: 30: 9: 21$ & $11.923 \dagger$ & 0.0077 \\
\hline
\end{tabular}

*Mann-Whitney U test.

†Pearson $\chi^{2}$ test.

$\mathrm{HBcrAg}, \mathrm{HBV}$ core related antigen; ISH, in situ hybridisation; M, median. 
A
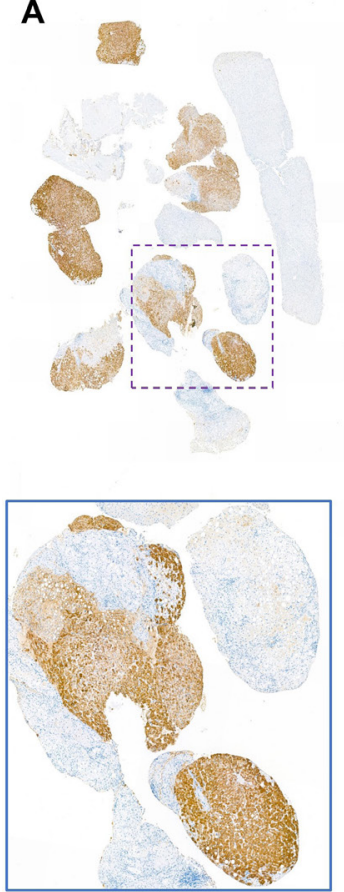

B
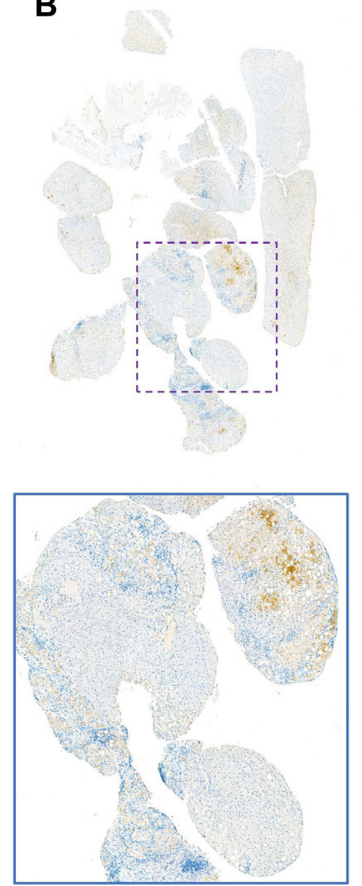

C
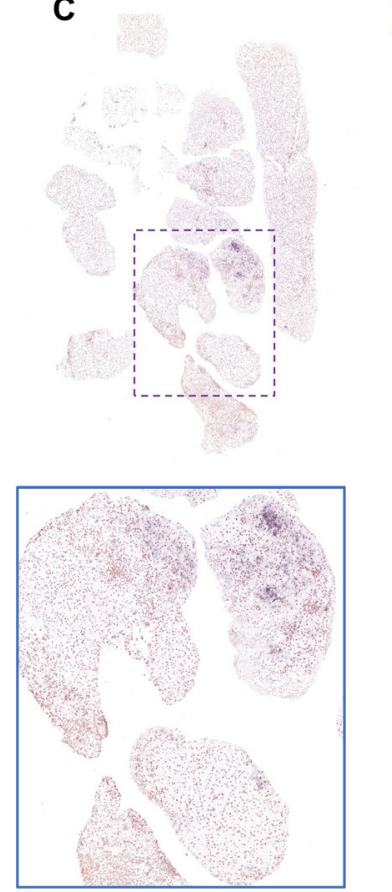

Figure 1 Head-to-head comparison of immunohistochemistry of surface antigen (A), core antigen (B) and in situ hybridisation of HBV DNA (C) in a HBeAg-positive CHB patient with HBV DNA of $5.89 \times 10^{6} \mathrm{IU} / \mathrm{mL}, \mathrm{HBsAg}$ of $2180 \mathrm{IU} / \mathrm{mL}$ and ALT of $45 \mathrm{U} / \mathrm{L}$. The whole section scanning image and respective areas (marked by rectangles) were enlarged and shown. ALT, alanine transferase; CHB, chronic hepatitis B; HBV, hepatitis B virus.

$(\mathrm{p}<0.001)$, which conforms to the clinical course of the disease. The median HBsAg titre in HBeAg-positive patients was 4.117 $\log 10 \mathrm{IU} / \mathrm{mL}$, significantly higher than that of HBeAg-negative ones $(3.296 \log 10 \mathrm{IU} / \mathrm{mL}, \mathrm{p}<0.0001)$. Similarly, serum HBV DNA level was significantly higher in HBeAg-positive patients (median, $7.314 \log 10 \mathrm{IU} / \mathrm{mL}$ ) than in HBeAg-negative ones (median, $3.588 \log 10 \mathrm{IU} / \mathrm{mL}, \mathrm{p}<0.0001$ ).

\section{Staining patterns of HBV DNA ISH and its relationship with serum biomarkers}

A total of 298 cases showed positive HBV DNA signal (positive rate 95.2\%), which is similar to IHC of HBsAg (97.1\%) and significantly higher than HBcAg (42.8\%). The ISH signal was mostly distributed in the cytoplasm of the hepatocytes although nuclear localisation was also seen. Additionally, we also performed the assay on sections from six patients with non-HBV hepatitis (hepatitis $\mathrm{C}$ and drug-induced hepatitis) and none of them exhibited positive staining. HBV DNA ISH assay showed 98.7\% positive rate in e antigen positive cases compared with 91.3\% in e negative ones. Similarly, HBsAg IHC showed 98.1\% positive rate in e positive cases, whereas $93.3 \%$ of the e negative cases showed positive staining. The most striking difference was observed in core IHC staining. $64.4 \%$ of e antigen positive cases showed positive HBcAg staining, whereas the figure was only $19.3 \%$ in e antigen negative ones.

A close examination of the ISH in conjunction with the IHC from the same samples revealed some interesting findings. Although HBsAg and HBV DNA both showed high rate of detection in these sections, the distribution of HBV DNA was strikingly different from that of HBsAg in most of the cases. Figure 1 showed the typical staining results from liver sections of an HBeAg-positive patient with viral load of $5.89 \times 10^{6} \mathrm{IU} / \mathrm{mL}$. The surface antigen was accumulated in some of the lobules, whereas the HBV DNA was enriched in distinct areas. However, when cytoplasmic HBcAg was detected, it was usually distributed in similar zones of HBV DNA positivity. Nevertheless, we found that HBcAg may not be present when HBV DNA is highly abundant (online supplementary figure 1 ) indicating the limited sensitivity of the current $\mathrm{HBcAg}$ IHC assay. There are also cases that showed negative IHC results in both $\mathrm{S}$ and Core antigen but detectable HBV DNA as shown in one example (online supplementary figure 2). Although both HBsAg and intrahepatic HBV DNA showed high detection rate, in cases with undetectable $S$ or HBV DNA, only two cases showed double negative, whereas the other cases exhibited either S (11 cases) or HBV DNA (13 cases) negativity. The cross-tabulation table results indicated that these two tests were independent of each other $(\mathrm{p}=0.1232$, Fisher's exact test, online supplementary table 1 ). By contrast, none of the HBV DNA ISH negative samples were positive for core antigen, whereas in HBV DNA ISH positive ones $(\mathrm{n}=298), 134$ of them showed core IHC positivity (44.6\%). Statistical analysis indicated that HBV DNA ISH positivity greatly increased the likelihood of positive core IHC result ( $p=0.0002$, Fisher's exact test, online supplementary table 2). These results suggested that HBcAg IHC was partially linked with HBV DNA ISH.

We next evaluated the correlation between intrahepatic DNA and other key parameters, that is, serum HBV DNA, HBcrAg and HBsAg titre. As shown, in figure 2A, a strong correlation pattern was observed between intrahepatic and circulating HBV DNA $\left(r_{s}=0.678, p<0.0001\right.$, figure $\left.2 A\right)$. Similarly, HBV DNA ISH signal is significantly correlated with $\mathrm{HBcrAg}$ level $\left(r_{s}=0.645, p<0.0001\right.$, figure $\left.2 B\right)$ and serum HBsAg titre $\left(r_{s}=0.531, p<0.0001\right.$ figure 2C).

We also compared the performance of HBV DNA ISH with those of routine IHC examinations. The HBV DNA positive rate was transformed into graded scores in order to make direct comparisons with IHC scores. First, although $\mathrm{HBcAg}$ IHC showed considerable positive correlation with serum viral markers (with viral load: $r_{s}=0.621$, with serum HBsAg: $r_{s}=0.580$, with HBcrAg: $r_{s}=0.666, p<0.0001$, figure $3 \mathrm{C}$ ), its low overall 
A

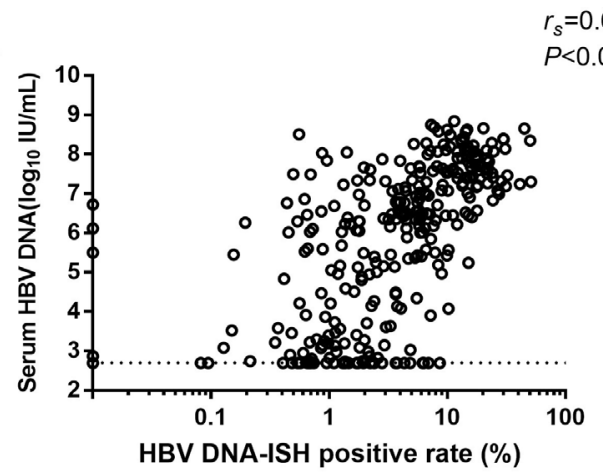

B

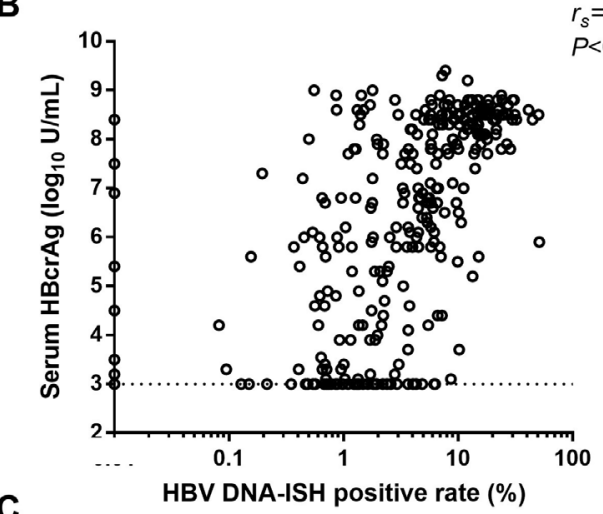

C

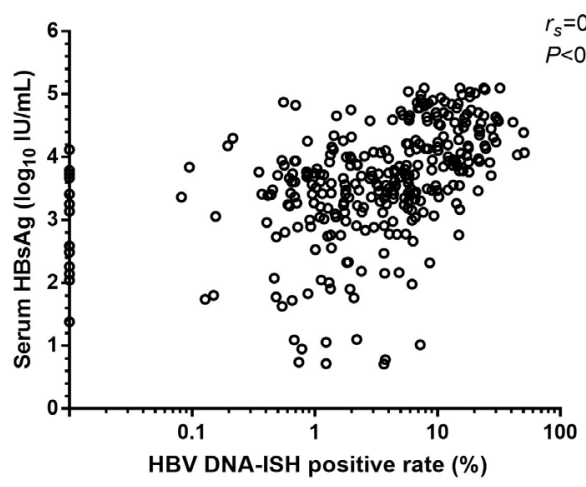

Figure 2 Correlation plots between HBV DNA ISH positive rate and serum HBV DNA (A), serum HBcrAg (B) and serum HBsAg (C). Spearman's rank correlation.P values were shown in each plot. $\mathrm{HBCrAg}$, HBV core related antigen; HBV, hepatitis B virus; ISH, in situ hybridisation.

positive rate $(42.8 \%)$ restricted its usefulness in patients with limited viral replication. The IHC of HBsAg, however, showed a high positive rate (97.1\%). Its relationships with circulating viral markers exhibited significantly lower correlations (with viral load: $r_{s}=0.437$, with serum HBsAg: $r_{s}=0.454$, with HBcrAg: $r_{s}=0.397, p<0.0001$, figure 3B) than those of HBV DNA ISH signal (with viral load: $r_{s}=0.678$, with serum HBsAg: $r_{s}=0.521$, with HBcrAg: $r_{s}=0.641, p<0.0001$, figure $3 \mathrm{~A}$ ).

Inter-relationships among serum and intrahepatic parameters We generated a correlation matrix among the serum and liver biomarkers stratified with $\mathrm{HBeAg}$ status (figure 4). Some significant trends were noted. The core-related antigen showed strong relationship with viral load (e positive patients, $r=0.838$, $\mathrm{p}<0.0001$; e negative patients, $\mathrm{r}=0.545, \mathrm{p}<0.0001)$ and viral surface antigen (e positive patients, $r=0.619, \mathrm{p}<0.0001$; e negative patients, $\mathrm{r}=0.462, \mathrm{p}<0.0001$ ) irrespective of $\mathrm{HBeAg}$
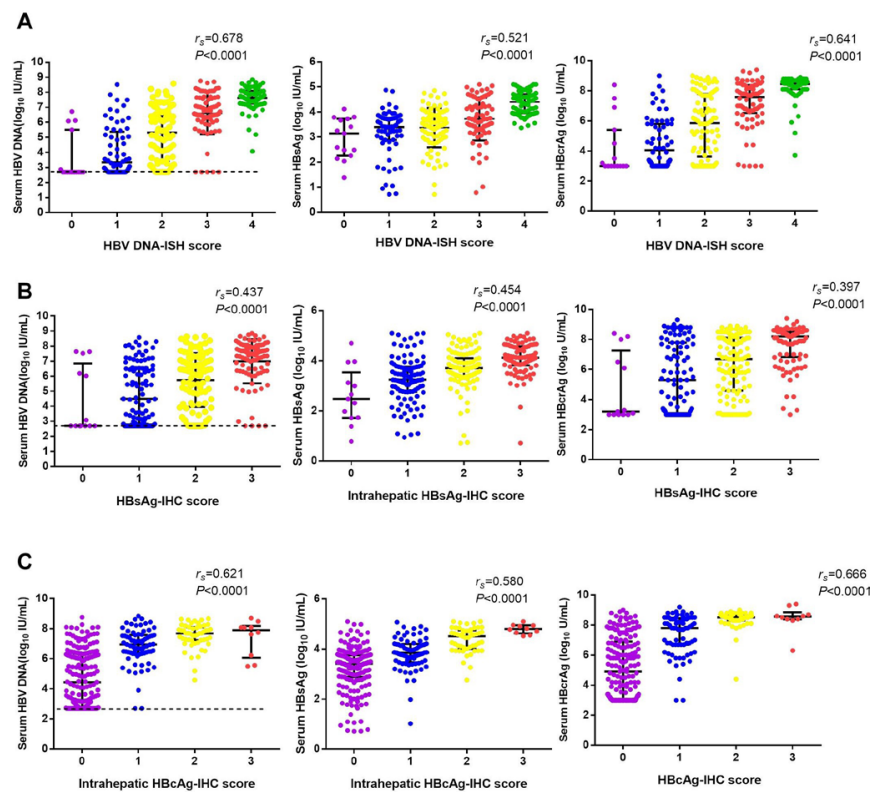

Figure 3 Relationship between intrahepatic virological markers and serum markers. The level of serum HBV DNA, serum HBsAg and $\mathrm{HBcrAg}$ were grouped according to ISH score for HBV DNA (A), IHC score for surface antigen (B) or core antigen (C) and were compared. $\mathrm{HBCrAg}, \mathrm{HBV}$ core related antigen; HBV, hepatitis B virus; IHC, immunohistochemistry; ISH, in situ hybridisation.

status(figure 4). By contrast, the $\mathrm{HBcAb}$ titre exhibited distinct relationship with HBV DNA ISH signal in e antigen positive $(\mathrm{r}=-0.31, \mathrm{p}<0.0001)$ and negative groups $(\mathrm{r}=0.28, \mathrm{p}<0.0001)$. Similar trends were also observed between $\mathrm{HBcAb}$ and serum HBV DNA (e positive patients, $\mathrm{r}=-0.34, \mathrm{p}<0.0001$; e negative patients, $\mathrm{r}=0.58, \mathrm{p}<0.0001$ ) or $\mathrm{HBcrAg}$ (e positive patients, $\mathrm{r}=-0.32, \mathrm{p}<0.0001$; e negative patients, $\mathrm{r}=0.44, \mathrm{p}<0.0001$ ) (figure 4). The relationship between serum ALT and intrahepatic DNA was also analysed. In e antigen positive group, no statistical significance was found between these markers $(r=-0.014$, $\mathrm{p}=0.85$ ) while in e negative group, a positive correlation was found $(\mathrm{r}=0.35, \mathrm{p}<0.0001)$.

Patterns of intrahepatic HBV DNA in different levels of liver inflammation and fibrosis

We also noted in the correlation matrix that the HBV DNA ISH signal had different patterns of correlation with liver histology if divided by HBeAg status. In HBeAg-positive patients, while liver inflammation is not related to intrahepatic DNA, the level of fibrosis is negatively related to HBV DNA ISH $\left(\mathrm{r}_{\mathrm{s}}=-0.166\right.$, $\mathrm{p}<0.05$, figure 5A). However, in HBeAg-negative patients, significant positive relationships were observed between intrahepatic HBV DNA and liver grade $(r=0.362, p<0.0001)$ and stage $(\mathrm{r}=0.277, \mathrm{p}=0.0006$, figure $5 \mathrm{~B})$. These results suggested the modulatory role of $\mathrm{HBeAg}$ on the development of liver pathologies in $\mathrm{CHB}$.

HBV DNA, HBsAg and Sirius red triple staining as a convenient molecular pathology examination on the virological and histological status of CHB

Since previous results suggested spatially distinct distribution of HBV DNA and HBsAg in accordance with our previous report, we sought to combine these two markers on one section by serially staining HBV DNA and HBsAg. Furthermore, we performed a Sirius red counterstain to provide a histological background of 
A

$\mathrm{HBeAg}(+)$

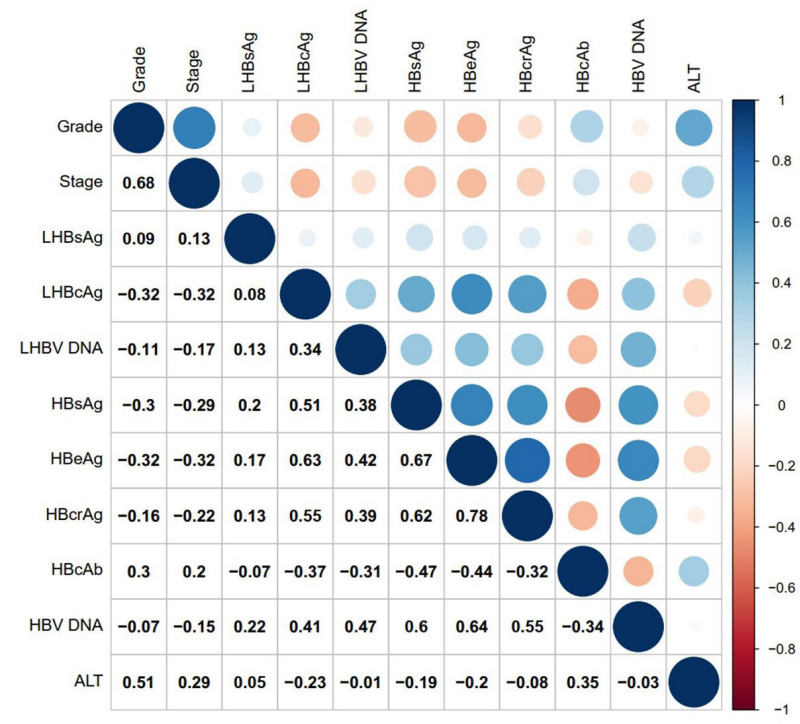

B

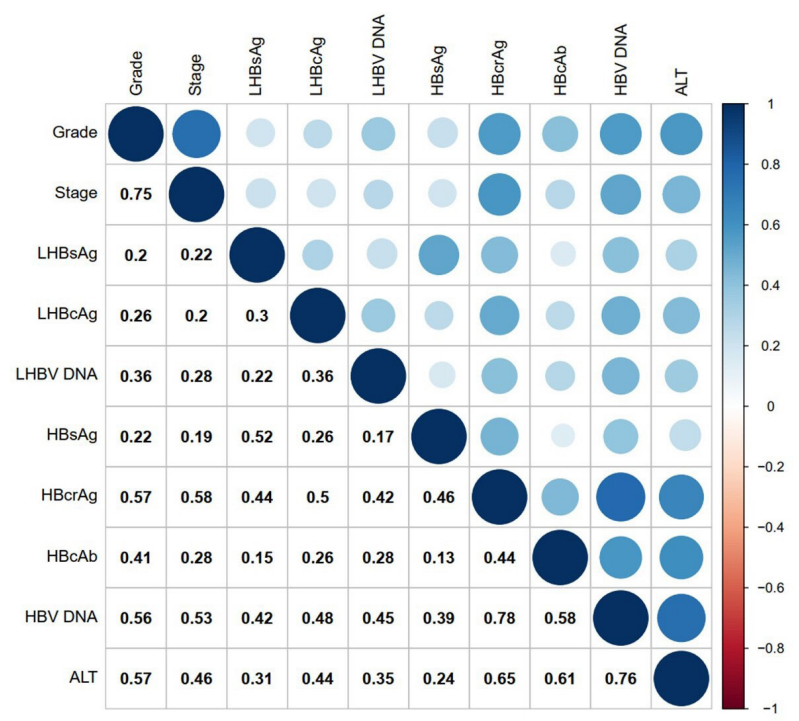

Figure 4 The correlation matrix between serological and intrahepatic variables of overall population (A), $\mathrm{HBeAg}$ population (B) and $\mathrm{HBeAg}$ negative polupation $(C)$. The circle colour indicates the value of Spearman correlation coefficients. Blue indicates positive correlation; red indicates positive correlation. ALT, alanine transferase; $\mathrm{HBV}$, hepatitis $B$ virus; $\mathrm{HBcrAg}$, $\mathrm{HBV}$ core related antigen.

collagen fibres. The blue purple (HBV DNA), brown (HBsAg) and red combination resulted in a high colour contrast, easy-tointerpret images (figure 6). Importantly, this triple stain revealed some interesting phenomena. The HBV DNA and HBsAg mostly exhibited a mutually exclusion pattern as we have reported. ${ }^{10}$ In addition, it was found that $\mathrm{S}$-rich cells mostly resided in minimally fibrotic region (figure 6A), while HBV DNA positive cells were frequently observed to be surrounded by collagen fibres (figure 6B-D). In some sections, transitions between S-rich and DNA-rich cells could be readily observed near the fibrotic region (figure 6E-F, note cells with both DNA and S signal). Collectively, the triple staining method provides pathologists a more
A

HBeAg +
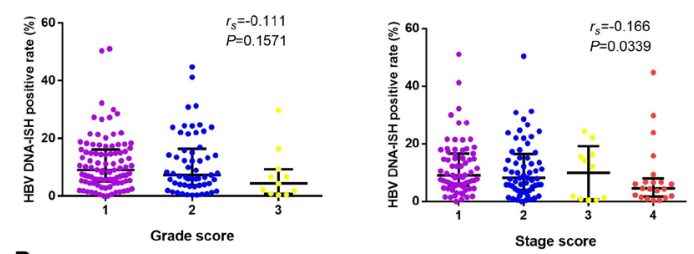

B

HBeAg -
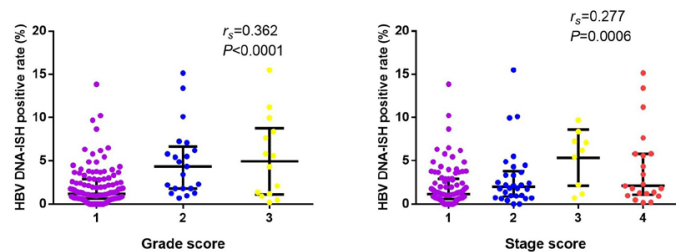

Figure 5 The relationship between HBV DNA ISH signal and liver inflammation and fibrosis. The cohort was stratified as HBeAg positive (A) and negative group (B), and the HBV DNA ISH positive rates were grouped according to liver grading and staging score. HBV, hepatitis $B$ virus; ISH, in situ hybridisation.

comprehensive view of the virological activities in relation to the histological progression of disease.

\section{DISCUSSION}

Although there have been some widely available blood biomarkers (viral load, quantitative $\mathrm{HBsAg}, \mathrm{HBeAg}$, serum biochemical parameters and so on) for evaluation of the chronic liver disease caused by HBV, liver histopathology offers a more direct view of the intrahepatic inflammatory fibrosis. In addition, immunostaining of viral antigens can reveal more details regarding the status of viral replication and virion/subviral particle production. Unfortunately, interpretation of these results was shown to be
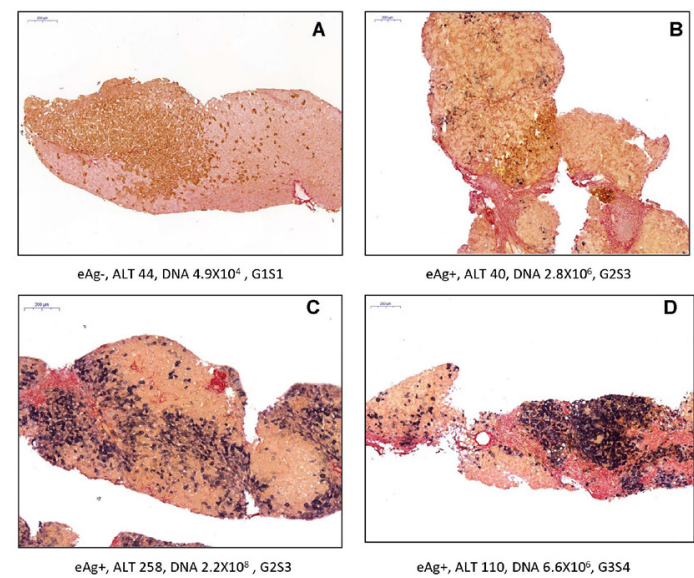

EAE+, ALT 258, DNA $2.2 \times 10^{8}$, G2S3

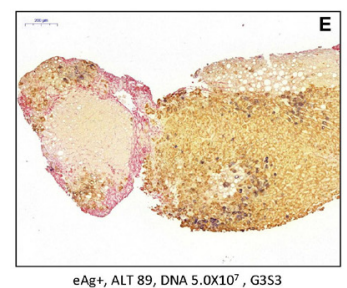

EAg+, ALT 110, DNA 6.6X10, G3S4

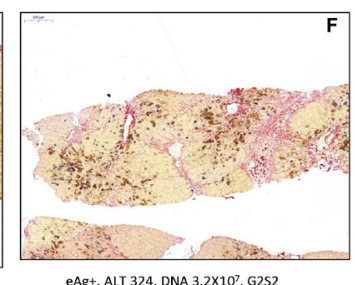

eAgt, ALT 324, DNA 3.2X107, G2S2

Figure 6 Typical images of the HBV DNA-HBsAg and Sirius red triple staining. A scale bar was shown for each panel. Basic clinical parameters such as HBeAg status, ALT (U/L), serum HBV DNA (IU/mL) and Scheuer score were listed. ALT, alanine transferase; HBV, hepatitis B virus. 
not straight forward. Previous studies found that IHC staining of surface antigen mostly generated a cytoplasmic signal arranged in clustered hepatocytes. When observed using H\&E staining, these cells exhibited eosinophilic, finely granular, rather dense cytoplasm resulting in a ground-glass appearance. ${ }^{11}$ This pattern is mostly observed in immune tolerant patients and carriers. However, IHC staining of core antigen can exhibit both nuclear and cytoplasmic pattern and showed much stronger relationship with acute lobular hepatitis and chronic active hepatitis. ${ }^{12-14}$ Indeed, we previously found a mosaic distribution of viral surface and core antigen together with HBV DNA, which suggested a more complex picture of HBV lifestyle at single-cell level. ${ }^{10}$ In this study, we applied the recently established HBV DNA in ISH assay in a large cohort of patients with $\mathrm{CHB}$ and compared its performance with well-established IHC assays.

Due to the extensive assay optimisation, our HBV DNA ISH assay generated a high rate of detection in CHB samples, which is comparable with that of HBsAg IHC, while preserving high specificity. In accordance with previous publication, the distribution of HBV DNA and surface antigen is largely different as shown in the head-to-head comparison of whole-section scans. However, cytoplasmic staining of core antigen showed much stronger spatial relationship with HBV DNA. However, IHC of core antigen is less sensitive as only $42.8 \%$ of the sections showed positivity.

We next evaluated the clinical relevance of HBV DNA ISH assay in the context of clinically available and novel biomarkers such as HBcrAg and HBcAb. We observed that HBV DNA ISH signal is highly correlated with serum viral load, $\mathrm{HBcrAg}$ and to a lesser extent, HBsAg titre. This pattern is shared by IHC of core antigen, although it has a much lower positive rate. Interestingly, the HBV DNA ISH signal displayed an HBeAg-dependent relationship with $\mathrm{HBcAb}$ titre. This trend was also found between viral load and $\mathrm{HBCAb}$. Indeed, quantitative core antibody levels were reported to be tightly associated with hepatitis activity, ${ }^{15}$ a process heavily influenced by HBeAg status.

Apart from the ISH of HBV DNA, we also developed a triple staining method in which, the viral replication, viral surface antigen expression and collagen fibre can be observed on the same section. This gives us a unique integrated view of disease progression and provides the important spatial relationship among virological and histological events, which is informative for both basic clinical research and accurate pathological diagnosis.

Taken together, based on a clinical group of $313 \mathrm{CHB}$ cases, ISH of HBV DNA exhibits a sensitivity and specificity similar to that of HBsAg IHC but with distinct histological distribution. It informs intrahepatic virological activity and correlates with

Take home messages

- The developed in situ hybridisation assay for hepatitis B virus (HBV) DNA showed high level of sensitivity and specificity in a cohort of 313 chronic hepatitis B cases.

- A novel triple staining protocol that combines the detection of HBV DNA, HBsAg and collagen fibre enables better evaluation of viral replication and antigen expression in the context of liver fibrosis. existing biomarkers. Hence, it shows promise as a novel molecular pathology examination for precision diagnosis of HBVinduced liver disease.

\section{Handling editor Tony Mazzulli.}

Contributors $Z Z, X Z$ and $Z Y$ conceived the study; $D L, T X, B S, W L$ and $Y Z$ performed the experiments; $Y F, Z Y, X Z$ and $Z Z$ analysed the data; $X Z$ wrote the manuscript; all authors reviewered and approved the manuscript.

Funding National Science and Technology Major project of China (2017ZX10203202, 2017ZX10302-201-001-005 and 2018ZX10305409-001005); National Natural Science Foundation (81671998 and 81873962); Shanghai Municipal Hospital of Joint Research Projects in Emerging Cutting-Edge Technology (SHDC12016237); Shanghai Science and Technology Commission (16411960100).

Competing interests None declared.

Patient consent for publication Not required.

Provenance and peer review Not commissioned; externally peer reviewed.

Data availability statement Data are available in a public, open access repository. Fully digitalised whole-section images accompanied by basic clinical parameters are available at http://www.hepb-atlas.com.

Open access This is an open access article distributed in accordance with the Creative Commons Attribution Non Commercial (CC BY-NC 4.0) license, which permits others to distribute, remix, adapt, build upon this work non-commercially, and license their derivative works on different terms, provided the original work is properly cited, appropriate credit is given, any changes made indicated, and the use is non-commercial. See: http://creativecommons.org/licenses/by-nc/4.0/.

\section{ORCID iD}

Xiaonan Zhang http://orcid.org/0000-0002-1286-7280

\section{REFERENCES}

1 Sarin SK, Kumar M, Lau GK, et al. Asian-Pacific clinical practice guidelines on the management of hepatitis B: a 2015 update. Hepatol Int 2016;10:1-98.

2 European Association for the Study of the Liver. Electronic address: easloffice@ easloffice.eu, European Association for the Study of the Liver. EASL 2017 clinical practice guidelines on the management of hepatitis B virus infection. J Hepatol 2017:67:370-98.

3 Revill PA, Chisari FV, Block JM, et al. A global scientific strategy to cure hepatitis B. Lancet Gastroenterol Hepatol 2019:4:545-58.

4 van Campenhout MJH, Brouwer WP, van Oord GW, et al. Hepatitis B core-related antigen levels are associated with response to entecavir and peginterferon add-on therapy in hepatitis B e antigen-positive chronic hepatitis B patients. Clin Microbiol Infect 2016:22:571:571.e5-571.e9.

5 Zhang Z-Q, Lu W, Wang Y-B, et al. Measurement of the hepatitis B core-related antigen is valuable for predicting the pathological status of liver tissues in chronic hepatitis B patients. J Virol Methods 2016:235:92-8.

6 Zhang Z-Q, Zhang X-N, Lu W, et al. Distinct patterns of serum hepatitis B corerelated antigen during the natural history of chronic hepatitis B. BMC Gastroenterol 2017;17:140.

7 Fan R, Sun J, Yuan Q, et al. Baseline quantitative hepatitis B core antibody titre alone strongly predicts $\mathrm{HBeAg}$ seroconversion across chronic hepatitis B patients treated with peginterferon or nucleos(t)ide analogues. Gut 2016:65:313-20.

8 Goodman ZD. Grading and staging systems for inflammation and fibrosis in chronic liver diseases. J Hepatol 2007:47:598-607.

9 Hsu HC, Su IJ, Lai MY, et al. Biologic and prognostic significance of hepatocyte hepatitis $B$ core antigen expressions in the natural course of chronic hepatitis $B$ virus infection. J Hepatol 1987:5:45-50.

10 Zhang X, Lu W, Zheng Y, et al. In situ analysis of intrahepatic virological events in chronic hepatitis B virus infection. J Clin Invest 2016;126:1079-92.

11 Hadziyannis S, Gerber MA, Vissoulis C, et al. Cytoplasmic hepatitis B antigen in "ground-glass" hepatocytes of carriers. Arch Pathol 1973:96:327-30.

12 Huang SN, Neurath AR. Immunohistologic demonstration of hepatitis B viral antigens in liver with reference to its significance in liver injury. Lab Invest 1979;40:1-17.

13 Ray MB, Desmet VJ, Bradburne AF, et al. Differential distribution of hepatitis B surface antigen and hepatitis B core antigen in the liver of hepatitis B patients. Gastroenterology 1976;71:462-9.

14 Gudat F, Bianchi L, Sonnabend W, et al. Pattern of core and surface expression in liver tissue reflects state of specific immune response in hepatitis B. Lab Invest 1975;32:1-9.

15 Song L-W, Liu P-G, Liu C-J, et al. Quantitative hepatitis B core antibody levels in the natural history of hepatitis B virus infection. Clin Microbiol Infect 2015;21:197-203. 